\title{
Influence of Sugars, Sugar Alcohols and Their Combinations on Environmentally Significant Cellulase Production Under Liquid State Fermentation
}

\author{
Nitin Verma*(***)† and Vivek Kumar**(***) \\ *Department of Biotechnology, Meerut Institute of Engineering \& Technology MIET, Meerut-250 005, U.P., India \\ **Biotechnology Division, CRDT, Indian Institute of Technology, Hauz Khas New Delhi-110 016, India \\ ***Department of Paper Technology, Indian Institute of Technology, Roorkee Saharanpur Campus, Saharanpur-247001, \\ U.P., India \\ †Corresponding author: Nitin Verma: nitin.verma@miet.ac.in; nitiniit2008@gmail.com
}

\author{
Nat. Env. \& Poll. Tech. \\ Website: www.neptjournal.com \\ Received: 16-01-2021 \\ Revised: 15-04-2021 \\ Accepted: 30-04-2021 \\ Key Words: \\ Cellulase \\ Sugar \\ Sugar alcohol \\ Inducer \\ Liquid state fermentation
}

\begin{abstract}
To expand the range of soluble carbon sources for enzyme production by the microbial system, we investigated the ability of different sugars in cellulase production. Carbon sources play a vital role in cell metabolism and the synthesis of cellulase. Although the insoluble cellulosic materials are considered the most effective natural inducers for cellulase production by microorganisms in terms of both enzyme yield and productivity, their insolubility causes many problems and presents a major drawback that is partly responsible for the high cost of cellulase production. Mostly, the insolubility of sugar polymer leads to difficult and complex fermentation operations, including sterilization, cell biomass measurement, mixing and aeration of the fermentation broth, continuous feeding/sampling, and subsequent enzyme purification. Second, cellulase gets absorbed into the solid cellulose surface, leading to enzyme loss. The present paper gives a comparative view on the utility of pure sugars (lactose, CMC, sucrose, maltose, cellobiose, xylose, trehalose, arabinose) and sugar alcohols (sorbitol, mannitol) on cellulase production by various fungal strains. It also describes the blending effect of sugars as well as sugar alcohols on cellulase production by fungal strains.
\end{abstract}

\section{INTRODUCTION}

Cellulase is an enzyme that is capable of hydrolyzing the complex organic form of cellulose into simple sugar (glucose). Sugars play a significant role in cellulase biosynthesis and act as an inducer (Lin et al. 2017). Cotoras \& Agosin (1992) found that brown rot fungus Gloeophyllum trabeum produced endoglucanases in the presence of monosaccharides such as glucose or mannose as the sole carbon source, but the expression of these enzymes was 4-5 times higher in the presence of cellulose or cellobiose. They concluded that endoglucanase production by brown rot fungi is inducible by cellulose and not subject to catabolite repression. Cellobiose is the most effective inducer of the system. Morikova et al. (1995) suggested lactose as an inducer for cellulase formation in Trichoderma reesei PC-3-7. Schaffner \& Toledo (1991) reported that cellulase activity was increased in conditions containing xylose supplemented with sorbose compared to xylose alone as a carbon source by $T$. reesei. Janas et al. (2002) reported that enzymatic activities of cellulases obtained by $T$. reesei M-7 in presence of lactobionic acid and lactose were about $20 \%$ higher than in the presence of only lactose. Thirumale et al. (2001) were the first to report trehalose as a cellulase biosynthesis inducer. Trehalose is the most effective inducer when compared to lactose and cellobiose. Lactose was also suggested by Sehnem et al. (2006) as an inducer in Penicillium echinulatum 9A0251 cellulase production. Cultures grown in lactose produced low FPA activity $\left(0.1\right.$ FPU.mL $\left.{ }^{-1}\right)$, whereas cultures grown on lactose with cellulose-containing media produced high enzyme activity (1.5 FPU. $\left.\mathrm{mL}^{-1}\right)$, implying that increasing the lactose/cellulose ratio results in a proportional rise in enzymatic activity. Morrison et al. (1987) discovered that Taloromyces emersonioi CBS 814.70 could grow on lactose-containing media when lactose was used as an inducer. Kamagata et al. (1991) reported cellulase production by Penicillium purpogenum strain P-26, which was strongly induced by cellobiose octaacetate (COA) in the presence of microcrystalline cellulose as a cosubstrate. A fraction of cello-oligosaccharides with a high degree of polymerization (GX) was found to be a potent cellulase inducer in Trichoderma koningii G-39 (Wang et al. 1988). T. reesei uses sophorose metabolism to induce cellulase production (Loewenberg \& Chapman 1997). Cellobiono1-5 lactone or oxidized cellulose, a cellulose degradation product, has also been shown to increase the synthesis of cellulase in 
T. reesei. (Cotoras \& Agosin 1992). Any soluble substrate with a -1-4 glucan linkage, such as carboxymethyl cellulose and cellobiose, produced induction, however, these are weaker inducers than cellulose itself. Cellulase biosynthesis has been observed to be induced by cellobiose, the smallest cellooligosaccarides with a -1-4 linkage. Surprisingly, sophorose, a glucose disaccharide with a -1-2 bond, can generate 2500 times more cellulase in $T$. reesei than cellobiose. Gentiobiose, a glucose disaccharide having a -1-6 bond, was discovered to produce 50 times more cellulase in Penicillium (Suto \& Tomita 2001). Cellulase produced on lactose was more than the cellobiose. Cellobiose is an excellent growth substrate for these fungi and is rapidly consumed, whereas lactose which differs from the cellobiose only in configuration around the number four carbon in the glucoside ring is a poor growth substrate for fungi and is poorly consumed. For most of the cellulase producers, the inducing rate of the inducers for cellulase production is as follows - Cellulose cellobiose octa acetate $>$ lactose $>$ cellobiose. Binder \& Ghosh (1978) claim that the actual contact between hyphae and cellulose is essential for cellulase induction. Sophorose is produced by the acid hydrolysis of starch, it is a potent inducer of cellulase in T. reesei. Both cellobiose and lactose are inducers, although cellobiose is more effective due to its high initial concentration. Glucosyl transfer products are present in the medium during cellobiose growth and are said to be greater inducers than cellobiose. Trichoderma viride and Neurospora crassa have different cellulase production systems. Sophorose and cellulose are the only two substances that have a substantial effect. The activity of the CMCase enzyme: CMCase is not induced by CMC, cellobiose, or lactulose; instead, it is induced by -glucosidase. Although lactose metabolism is slower than cellulose, lactose is an important carbon source for the fungus $T$. reesei, which produces cellulolytic enzymes (Wang \& Reesei 1994). In a continuous culture of T. reesei, Ju \& Afolabi (1999) tested the potential of waste paper hydrolysate to induce cellulase and employed it as a soluble substrate for cellulase synthesis. Wyman \& Chen (1992) looked at soluble inducers obtained from whole wheat flour for T. reesei cellulase synthesis. Wyman \& Chen (1991) have described cellulase production using a carbon source sourced from discarded office paper, which serves as both raw material and an inducing agent. Lactose is a low commercial cost disaccharide and also acts as the source of carbon and inducer for cellulase production by fermentation (Sehnem et al. 2006). Soluble carbon sources such as lactose, cellobiose give significantly lower cellulase activity compared to pure insoluble cellulosic substances such as cotton, avicel, solka floc at the same concentration (Morikova et al. 1995, Bhatt 2000). Niranjane et al. (2007) investigated the influence of different carbohydrates such as glucose, xylose, carboxymethyl cellulose (CMC), microcrystalline cellulose (avicel), and cellobiose as carbon sources for the production of cellulase by Phlebia gigantea fungus. Carboxymethyl cellulose gave the highest yield, followed by cellobiose and avicel. Glucose and xylose did not produce any detectable cellulases which suggest the repression of cellulase in the presence of these simple carbohydrates by $P$. gigantea. Several substrates have been used for the fermentative production of cellulase. Although the insoluble cellulosic materials are considered the most effective natural inducers for cellulase production by microorganisms in terms of both enzyme yield and productivity, their insolubility causes many problems and presents a major drawback that is partly responsible for the high cost of cellulase production. Mostly, the insolubility of sugar polymer leads to complex fermentation operations such as sterilization, cell biomass measurement, mixing/aeration of the fermentation broth, continuous feeding/sampling, and subsequent enzyme purification. It also creates the adsorption of cellulase onto the solid cellulose surface, leading to enzyme loss. The use of soluble sugars and sugar alcohols to handle such fermentation activities based on limits would be useful. The present paper emphasized the utility of various sugars (lactose, CMC, cellobiose, sucrose, maltose, xylose, arabinose, trehalose) and sugar alcohols (sorbitol, mannitol) in cellulase production by fungal strains under liquid state fermentation. It also portrays the effect of mixed pure sugars as well as sugar alcohols on cellulase production by various fungal strains.

\section{MATERIALS AND METHODS}

\section{Materials}

Chemicals: Chemicals used in the experimental studies were AR grade and of Himedia, Merck and Sigma Aldrich make.

Microorganisms: Five standard fungal strains, Trichoderma reesei NCIM 1186, Trichoderma viride NCIM 1195, Aspergillus niger NCIM 777, Aspergillus fumigatus NCIM 902, and Neurospora crassa NCIM 1021 were procured from National Chemical Laboratory (NCL), Pune, India.

Media for Culture Development: Potato dextrose agar (PDA) medium was used for culture development and maintenance of Trichoderma and Aspergillus strains, whereas Neurospora strain was developed and maintained on $\mathrm{M}_{2}$ agar medium as recommended by National Chemical Laboratory, Pune. PDA medium contains $\left(\mathrm{g} . \mathrm{L}^{-1}\right)$ Peeled potato, 200; Dextrose, 20; Yeast extract, 0.1; Agar 15 at pH 5.6. $\mathrm{M}_{2}$ agar medium contains (g.L $\mathrm{L}^{-1}$ ) Glucose, 10; Glycerine, 10; Yeast extract, 5; $\mathrm{KH}_{2} \mathrm{PO}_{4}, 0.3 ; \mathrm{MgSO}_{4} .7 \mathrm{H}_{2} \mathrm{O}, 0.1$; Agar, 20 at $\mathrm{pH} 6.8$.

Production of Media for Submerged Fermentation: 
In $\left(\mathrm{g} . \mathrm{L}^{-1}\right)$; Urea, 0.3; $\left(\mathrm{NH}_{4}\right)_{2} \mathrm{SO}_{4}, 1.4 ; \mathrm{KH}_{2} \mathrm{PO}_{4}, 2.0$; $\mathrm{MgSO}_{4} .7 \mathrm{H}_{2} \mathrm{O}, 0.3$; Peptone, 1.0 ; Tween80, 0.2; $\mathrm{FeSO}_{4} .7 \mathrm{H}_{2} \mathrm{O}$, $0.005 ; \mathrm{MnSO}_{4} .7 \mathrm{H}_{2} \mathrm{O}, 0.0016 ; \mathrm{ZnSO}_{4} .7 \mathrm{H}_{2} \mathrm{O} ; 0.0014$; $\mathrm{CaCl}_{2} \cdot 2 \mathrm{H}_{2} \mathrm{O} ; \mathrm{CoCl}_{2} \cdot 6 \mathrm{H}_{2} \mathrm{O}, 0.02$ and pure sugar 10.0., pH 5.0.

\section{Methods}

\section{Maintenance of Stock Culture}

The stock culture of Trichoderma, Aspergillus, and Neurospora strains were maintained on potato dextrose agar slants and $\mathrm{M}_{2}$ agar slant respectively. The same media was also used for subculturing of the respective fungal strains. The procured fungal stock was kept at $40^{\circ} \mathrm{C}$ in $20 \%$ (v/v) glycerol.

\section{Inoculum Development}

Inoculum development experiments were performed in 250 $\mathrm{mL}$ Erlenmeyer flasks containing $100 \mathrm{~mL}$ of Potato Dextrose Broth (PDB) medium (in g. $\mathrm{L}^{-1}$ ) Peeled Potato - 200; Dextrose - 20; and Yeast extract - 0.1) and $\mathrm{M}_{2}$ broth medium in which 5 loopful cultures of fungal spores or mycelial conidia were added and shaken at $180 \mathrm{rpm}$ at $30^{\circ} \mathrm{C}$ in an incubator shaker for 3-4 days (Domingues et al. 2004). A definite volume of prepared cultures in $\mathrm{PDB}$ or $\mathrm{M}_{2}$ broth suspension (having $0.56 \mathrm{~g} . \mathrm{L}^{-1}$ cell dry weight) was used as inoculum for further production studies.

\section{Submerged Fermentation}

Separate set of batch experiments were carried out in 250 $\mathrm{mL}$ Erlenmeyer flasks containing $100 \mathrm{~mL}$ of production media having components (in g.L $\left.{ }^{-1}\right)$ Urea - 0.3; $\left(\mathrm{NH}_{4}\right)_{2} \mathrm{SO}_{4}$ - 1.4; $\mathrm{KH}_{2} \mathrm{PO}_{4}$ - 2.0; $\mathrm{MgSO}_{4} .7 \mathrm{H}_{2} \mathrm{O}$ - 0.3; Peptone - 1.0; Tween 80 - 0.2; $\mathrm{FeSO}_{4} .7 \mathrm{H}_{2} \mathrm{O}-0.005 ; \mathrm{MnSO}_{4} .7 \mathrm{H}_{2} \mathrm{O}-0.0016$; $\mathrm{ZnSO}_{4} \cdot 7 \mathrm{H}_{2} \mathrm{O}-0.0014 ; \mathrm{CaCl}_{2} \cdot 2 \mathrm{H}_{2} \mathrm{O}, \mathrm{CoCl}_{2} \cdot 6 \mathrm{H}_{2} \mathrm{O}-0.02$; Pure sugars or sugar alcohols or mixtures -10 .

Flasks containing production media with different pure sugars, sugar alcohols, or their mixtures are used separately for cellulase production by various fungal strains under liquid state fermentation. Each production media contacting flasks were autoclaved, cooled, and then inoculated with a specific volume having (0.56 g. $\mathrm{L}^{-1}$ cell dry weight) of PD and M2 broth culture solution of respective strains. The autoclaved and inoculated flasks were placed in an incubator shaker at $30^{\circ} \mathrm{C}$ at $180 \mathrm{rpm}$ for 5 days.

\section{Cellulase Activity}

Filter paper activity (FPA) and carboxymethyl cellulase (CMCase) were determined by the method recommended by Ghose (1987).

\section{RESULTS AND DISCUSSION}

Sugar plays a vital and critical role in cellulase biosynthesis as it acts as an inducer. Soluble carbon sources such as lactose, cellobiose give significantly lower cellulase activity compared to pure insoluble cellulosic substances such as cotton, avicel, solka floc at the same concentration. Many substrates have been utilized for the fermentative production of cellulase. Various purified cellulose such as avicel, solka floc, and cotton have been used as a carbon source for cellulase production (Allan \& Roche 1989, Schaffner \& Toledo 1991). For large-scale production of the enzyme, pure cellulose would be too costly and expensive to be applied in large-scale processes.

\section{Effect of Lactose on Cellulase Production under Submerged Cultivation}

Separate sets of batch experiments have been performed to study the effect of pure sugar such as lactose $\left(10\right.$ g.L $\left.\mathrm{L}^{-1}\right)$ as a carbon source on cellulase production by various fungal strains under submerged cultivation. It was observed from Figs. 1 (a) and 1(b) that fungal strains produced significantly good cellulase activities under a lactose-based fermentation medium. When cellulase activity was measured using a lactose-based medium, it was discovered that fungal strains produced much reduced cellulase activity. This could be related to lactose disaccharide's soluble nature, as literature has shown that soluble carbon sources have much lower cellulase activity than pure insoluble cellulosic compounds at the same pH concentrations (Morikova et al. 1995, Bhatt 2000).

The maximum cellulase activities (IU.mL ${ }^{-1}$ ) in terms of FPA and CMCase achieved by $T$. reesei, $T$. viride, $N$. crassa, A. niger and A. fumigatus were $2.31,1.63 ; 1.26,2.55$; $1.06,2.13 ; 0.433,1.96 ; 0.556,1.98$ at 120,$96 ; 144,144 ; 144$, $120 ; 96,72 ; 96,72 \mathrm{~h}$ respectively under lactose-based fermentation medium. It has been observed from Fig 1(a) that $T$. reesei produced higher FPA activity under lactose-based fermentation medium as compared to the other fungal strains, which states that lactose acts as a better inducer for cellulase production by $T$. reesei. Li et al. (2017) reported cellulase hyperproduction by $T$. reesei mutant SEU-7 on lactose. A sharp increment in FPA activities was observed after 48, 72, and $96 \mathrm{~h}$ by $T$. reesei, T. viride, and N.crassa strains. Ivanova et al. (2013) suggested that lactose permease is the main component essential for cellulase induction. On the other hand, higher CMCases were achieved by $T$. viride followed by $N$. crassa and $A$. niger fungal strains. A sharp increment has been observed in CMCase activity till $72 \mathrm{~h}$ by A. niger while a steep increment has been observed in CMCase after $72 \mathrm{~h}$, as viewed from Fig. 1(b). 


\section{Effect of CMC as a Carbon Source on Cellulase Production under Submerged Cultivation}

Individual sets of batch experiments have been performed to study the effect of carboxy methyl cellulose $\left(10\right.$ g. $\left.\mathrm{L}^{-1}\right)$ as a carbon source on cellulase production by various fungal strains under submerged cultivation. It was observed from Figs. 2(a) and 2(b) that various fungal strains produce significantly better cellulase activities under carboxymethylcellulose-based fermentation medium. Maximum cellulase activities (IU.mL ${ }^{-1}$ ) in terms of FPA and CMCase attained by $T$. reesei, $T$. viride, $N$. crassa, A. niger and $A$. fumigatus were $2.46,1.83 ; 1.31,3.08 ; 0.986,1.89 ; 0.523$, $2.41 ; 0.603,2.23$ at 120, 96; 120, 144; 144, 120; 120, 120; 96,120 h respectively under carboxymethylcellulose-based fermentation medium. It has been observed from Fig. 2(a) that T.reesei and T.viride produce higher FPA under CMC- based fermentation medium as compared to the other fungal strains. Waghmare et al. (2018) used CMC as a substrate for cellulase production by cellulolytic isolate Enterobactor sp. SUK-Bio. A steep increment in FPA was observed after $72 \mathrm{~h}$ by $T$. reese $i$ which suggests that up to $72 \mathrm{~h}, T$. reesei used energy for their growth, and after this period microbes used all the energy for enzyme production and reached their maximum at $120 \mathrm{~h}$ of the fermentation period. Niranjane et al. (2007) reported that carboxymethyl cellulose gave the highest yield, followed by cellobiose and avicel. On the other hand, higher CMCases were achieved by $T$. viride followed by Aspergillus strains. A steep increment in the CMCase has been observed until $72 \mathrm{~h}$ by $T$. viride and Aspergillus strains as viewed from Fig. 2(b).

\section{Effect of Cellobiose on Cellulase Production under Submerged Cultivation}

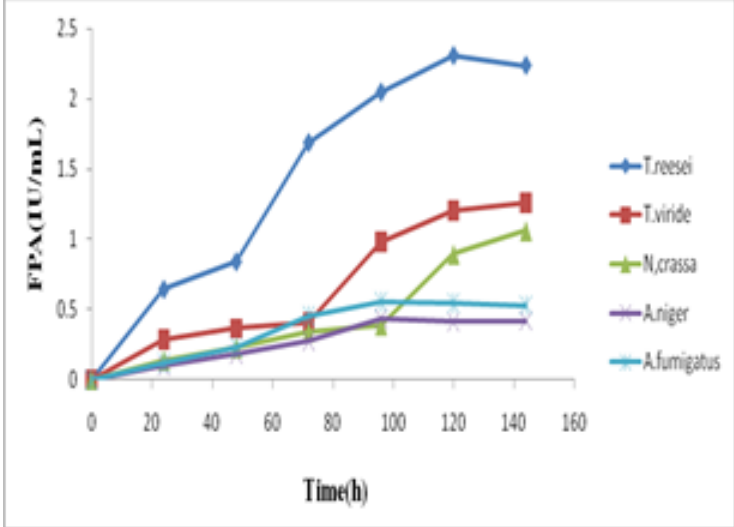

1(a)

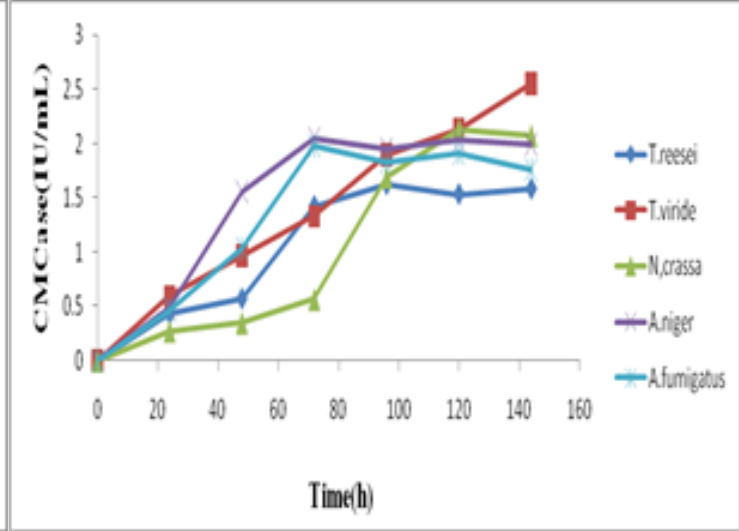

1(b)

Fig. 1: Comparative FPA and CMCase achieved by various fungal strains under lactose-based production medium at $30^{\circ} \mathrm{C}$ and $\mathrm{pH} 5.0$.

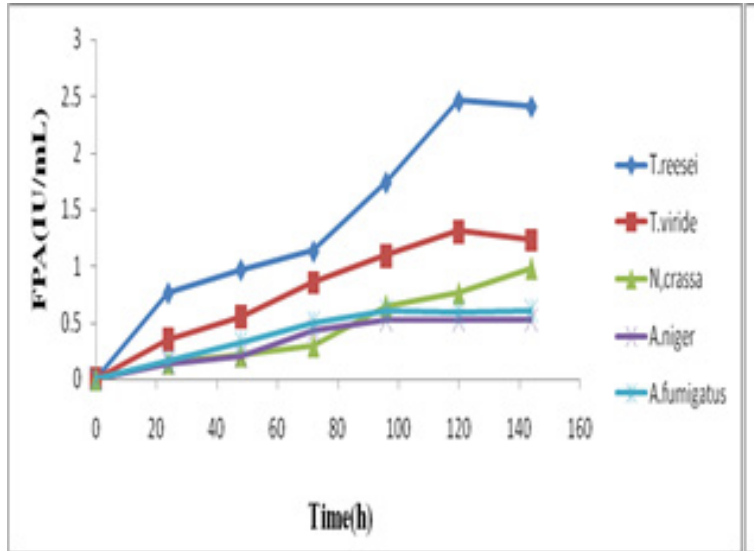

2(a)

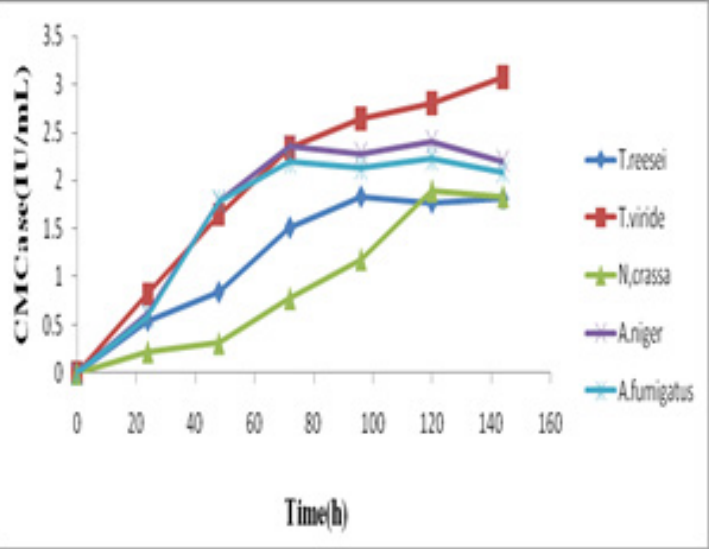

2(b)

Fig. 2: Comparative FPA and CMCase achieved by various fungal strains under CMC-based production medium at $30^{\circ} \mathrm{C}$ and $\mathrm{pH} 5.0$. 
Individual sets of batch experiments have been performed to study the effect of cellobiose $\left(10\right.$ g. $\left.\mathrm{L}^{-1}\right)$ as a carbon source on cellulase production by various fungal strains under submerged cultivation. It was observed from Figs. 3(a) and 3(b) that various fungal strains produce a significant amount of cellulase activities under a cellobiose-based fermentation medium. Maximum cellulase activities (IU.mL ${ }^{-1}$ ) in terms of FPA and CMCase attained by T.reesei, T.viride, N.crassa, $A$. niger and A.fumigatus were $2.02,1.75 ; 1.08,2.81 ; 0.955$, $1.92 ; 0.795,3.72 ; 0.885,3.19$ at 120,$96 ; 120,144 ; 144,120$; 96,$72 ; 120 ; 96,120 \mathrm{~h}$ respectively under cellobiose-based fermentation medium. It has been observed from Fig. 3(a) that T.reesei produces higher FPA activity under cellobiose-based fermentation medium as compared to the other fungal strains but when compared the cellulases produced by $T$. reesei under cellulose, lactose, and CMC, somewhat lower activity was observed under cellobiose-based fermentation medium as compared to other sugar-based media. FPA produced by Aspergillus strains were higher under cellobiose-based medium as compared to other sugars while the performance of N.crassa strain was found lower in cellobiose-based fermentation medium as compared to other sugar-based media as observed from Fig. 3(b).

\section{Effect of Sucrose on Cellulase Production Under Submerged Cultivation}

Separate sets of batch experiments have been performed to study the effect of sucrose $\left(10 \mathrm{~g} . \mathrm{L}^{-1}\right)$ as a carbon source on cellulase production by various fungal strains under submerged cultivation. It was observed from Figs. 4(a) and 4(b) that various fungal strains produce significant cellulase activities under the sucrose-based fermentation medium. Ike \& Tokuyasu (2018) investigated cellulase production of $T$. reesei using sucrose as a primary carbon source.

Maximum cellulase activities (IU.mL ${ }^{-1}$ ) in terms of FPA and CMCase attained by $T$. reesei, $T$. viride, N. crassa, A. niger and A. fumigatus were $1.93,1.71 ; 1.01,2.46 ; 1.18$, $2.36 ; 0.401,1.97 ; 0.483,1.81$ at 120,$96 ; 120,144 ; 144$, $120 ; 96,72 ; 96,72 \mathrm{~h}$ respectively under sucrose-based fermentation medium. It has been observed from Fig. 4(a) that $T$. reesei, $T$. viride, and $N$. crassa yield higher FPA activity under a sucrose-based fermentation medium as compared to Aspergillus strains. On the other hand, higher, CMCases were achieved by T.viride and N.crassa strains under sucrose-based fermentation medium as viewed from Fig. 4(b). Overall we can infer that Trichoderma, as well as Neurospora strains, performed better under sucrose-based fermentation medium in terms of cellulase production as compared to Aspergillus strains.

\section{Effect of Maltose Sugar on Cellulase Production Under Submerged Cultivation}

Separate sets of batch experiments have been performed to study the effect of maltose $\left(10 \mathrm{~g} . \mathrm{L}^{-1}\right)$ as a carbon source on cellulase production by various fungal strains under submerged cultivation. It was observed from Figs. 5(a) and 5(b) that various fungal strains produce significantly better cellulase activities except for Trichoderma under maltose-based fermentation medium. Maximum cellulase activities (IU. $\mathrm{mL}^{-1}$ ) in terms of FPA and CMCase attained by T. reesei, $T$. viride, N. crassa, A. niger and A. fumigatus were 1.13, 1.21; $0.698,1.91 ; 1.43,2.78 ; 0.571,2.81 ; 0.685,2.51$ at 120,96 ;

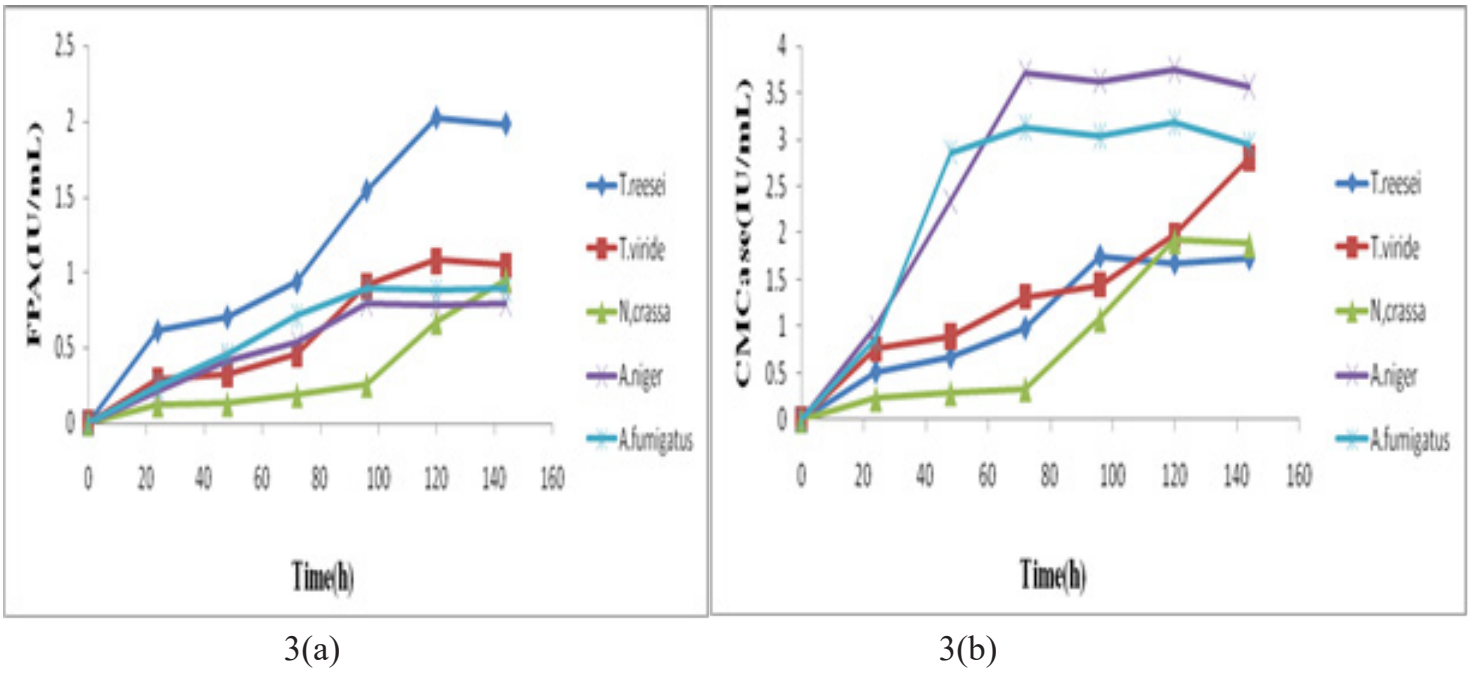

Fig. 3: Comparative FPA and CMCase achieved by various fungal strains under cellobiose based production medium at $30^{\circ} \mathrm{C}$ and $\mathrm{pH} 5.0$. 


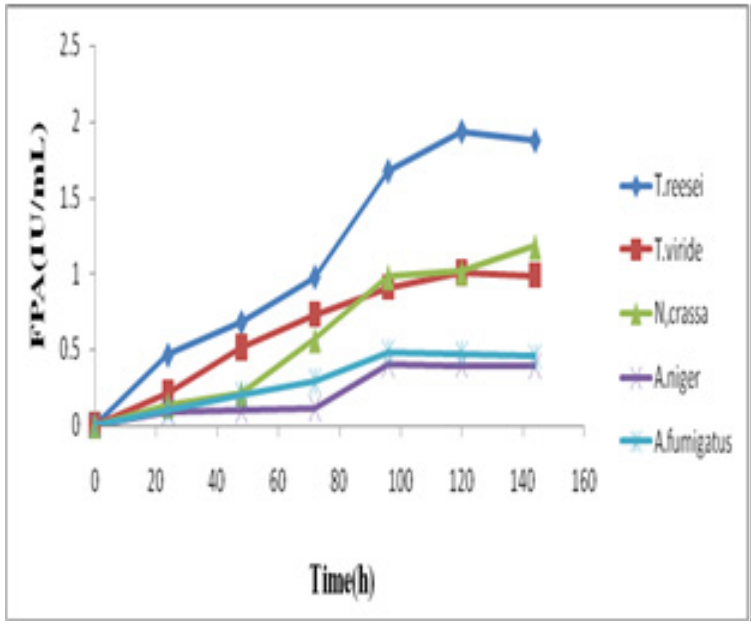

4(a)

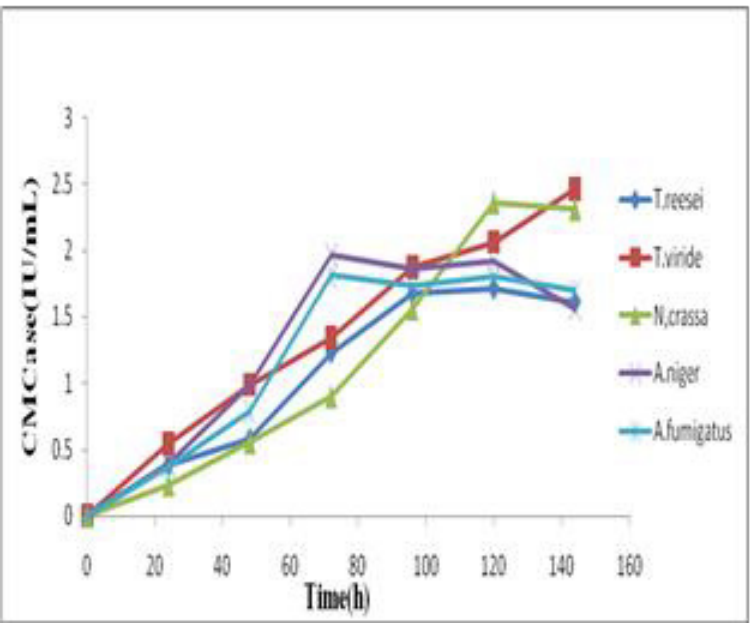

4(b)

Fig. 4: Comparative FPA and CMCase achieved by various fungal strains under sucrose based production medium at $30^{\circ} \mathrm{C}$ and $\mathrm{pH} 5.0$

120,$144 ; 144,120 ; 96,72 ; 96,72 \mathrm{~h}$ respectively under maltose-based fermentation medium. It has been observed from Fig. 5(a) that N.crassa produces higher FPA activity under a maltose-based fermentation medium as compared to the other fungal strains. Good improvement in FPAs activity of Aspergillus strains was observed in the maltose-based medium as compared to the sucrose-based fermentation medium. On the other hand, higher CMCases were achieved by Aspergillus as well as Neurospora strains. A steep increment in the CMCase has been observed until $48 \mathrm{~h}$ by Aspergillus strains as viewed from Fig. 5(b).

The effect of carbon sources such as glucose, sucrose, cellulose, carboxymethyl cellulose, and maltose on the pro- duction of enzymes by A. niger and Trichoderma sp. was investigated by Gautam et al. (2011). Significant cellulase activity was reported under cellulose, CMC, sucrose, and maltose-based fermentation.

\section{Effect of Xylose as Carbon Source on Cellulase Production Under Submerged Cultivation}

Individual sets of batch experiments have been performed to study the effect of xylose $\left(10\right.$ g.L $\left.\mathrm{L}^{-1}\right)$ as a carbon source on cellulase production by various fungal strains under submerged cultivation. Schuerg et al. (2017) reported that Xylose induces both cellulase and xylanase production in T. aurantiacus. It was observed from Figs. 6(a) and 6(b) that various fungal
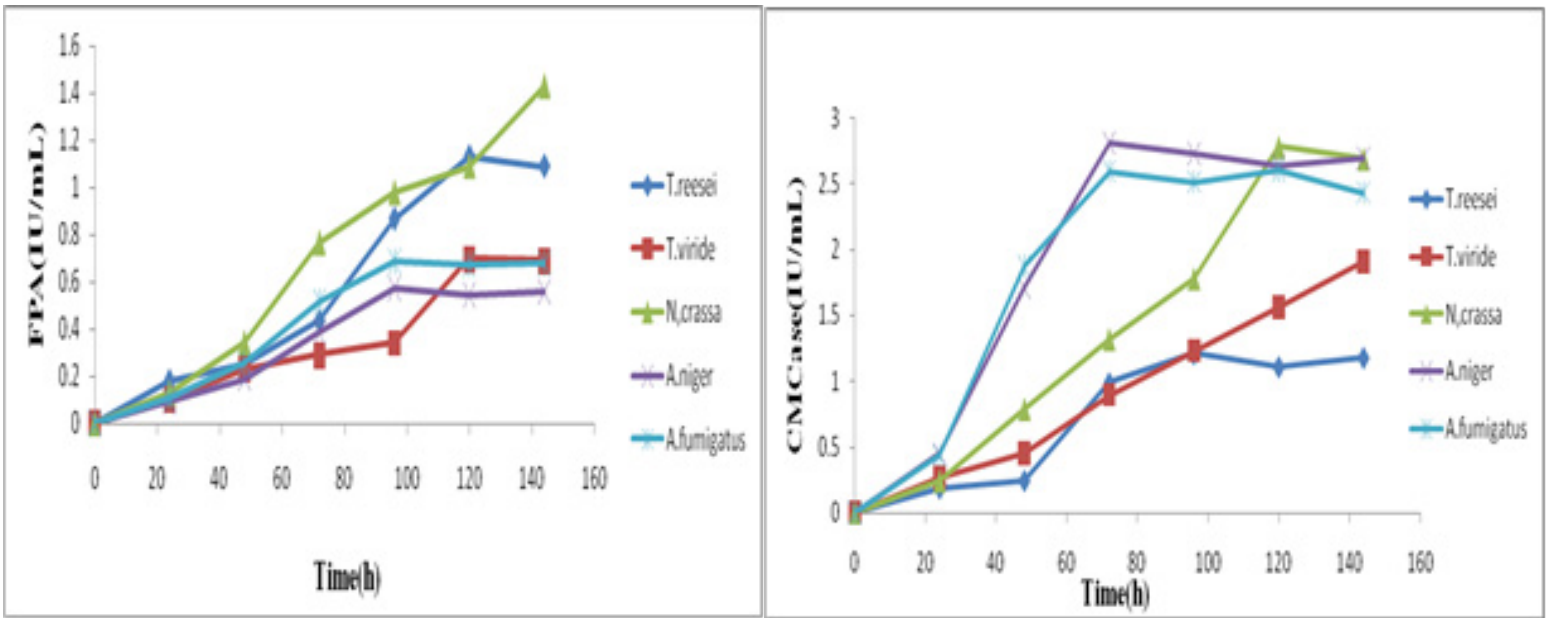

Fig. 5: Comparative FPA and CMCase achieved by various fungal strains under maltose based production medium at $30^{\circ} \mathrm{C}$ and $\mathrm{pH} 5.0$. 
strains produce significantly lesser cellulase activities except for Trichoderma strains. Maximum cellulase activities (IU. $\mathrm{mL}^{-1}$ ) in terms of FPA and CMCase attained by T. reesei, $T$. viride, N. crassa, A. niger and A. fumigatus were 1.53, 1.15; $0.780,1.54 ; 0.639,1.30 ; 0.239,1.21 ; 0.341,1.29$ at 120 , $96 ; 96,120 ; 144,144 ; 96,72 ; 96,72$ h respectively under xylose based fermentation medium. It has been observed from Fig. 6(a) that higher FPA activity was produced by $T$. reesei under a xylose-based fermentation medium as compared to the other fungal strains. A steep increment in FPA was observed after $96 \mathrm{~h}$ by $T$. reese $i$ which suggests that up to $96 \mathrm{~h} T$. reesei used energy for their growth and after this period microbes used all the energy for enzyme production and reached their maximum at $120 \mathrm{~h}$ of the fermentation period. On the other hand, higher CMCases were achieved by $T$. viride. A steady increment in the CMCase has been observed until $120 \mathrm{~h}$ by $T$. viride strain as viewed from Fig. 6(b). Maibam \& Maity (2019) developed a strategy for simultaneous xylose utilization and enhancement in cellulase enzyme production by $T$. reesei.

\section{Effect of Arabinose as Carbon Source on Cellulase Production Under Submerged Cultivation}

Separate sets of batch experiments have been performed to study the effect of arabinose pure sugar $\left(10 \mathrm{~g} . \mathrm{L}^{-1}\right)$ as a carbon source on cellulase production by various fungal strains under submerged cultivation. It was observed from Figs. 7(a) and 7(b) that various fungal strains produce significantly reduced cellulase activities under arabinose-based fermentation medium. Maximum cellulase activities (IU.mL ${ }^{-1}$ ) in terms of FPA and CMCase attained by $T$. reesei, $T$. viride, $N$. crassa, A. niger and A. fumigatus were 0.693, 0.490; 0.402,

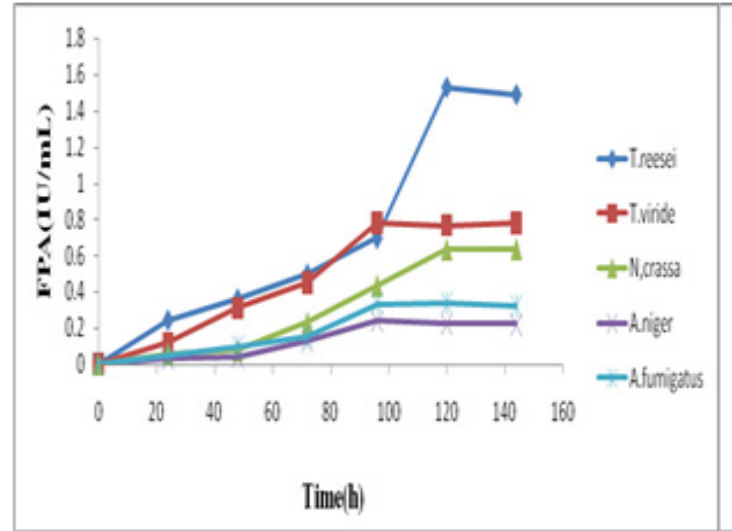

6(a)

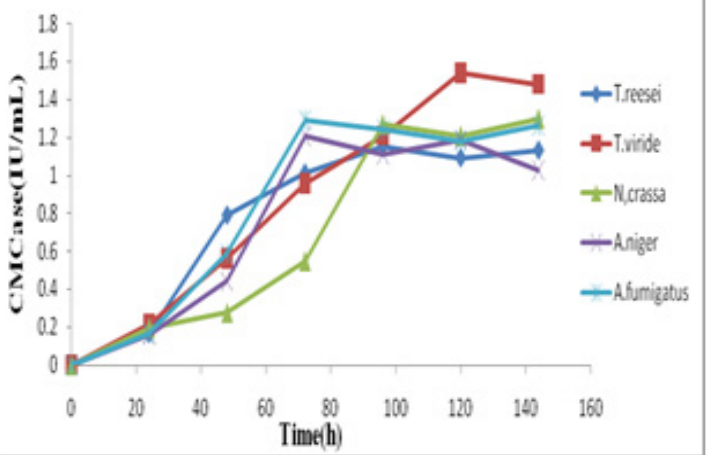

6(b)

Fig. 6: Comparative FPA and CMCase achieved by various fungal strains under xylose based production medium at $30^{\circ} \mathrm{C}$ and $\mathrm{pH} 5.0$.

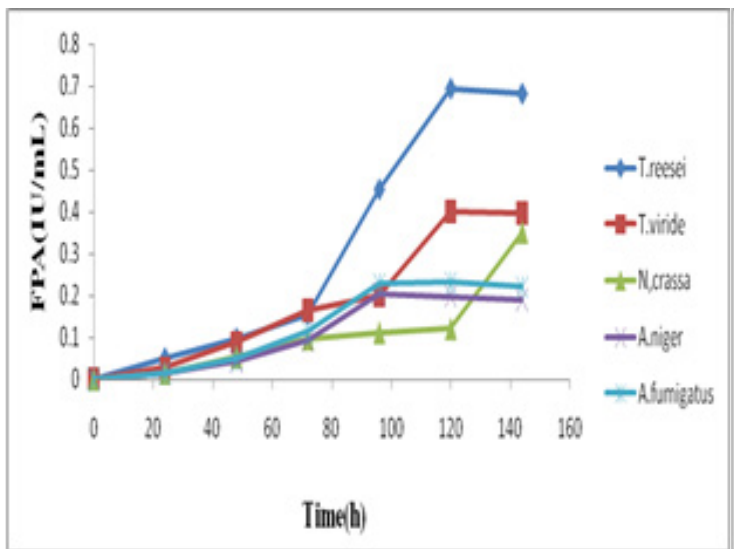

7(a)

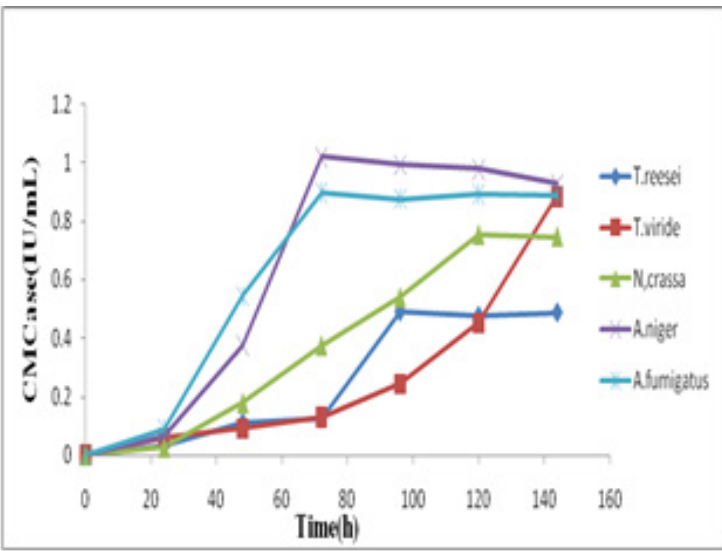

7(b)

Fig. 7: Comparative FPA and CMCase achieved by various fungal strains under arabinose based production medium at $30^{\circ} \mathrm{C}$ and $\mathrm{pH} 5.0$. 
$0.886 ; 0.351,0.755 ; 0.203,1.02 ; 0.231,0.896$ at 120,96 ; 120,$144 ; 144,120 ; 120,96 ; 120,72$ h respectively under arabinose based fermentation medium. It has been observed from Fig. 7(a) that higher FPA activity was produced by $T$. reese $i$ under an arabinose-based fermentation medium as compared to the other fungal strains. A steep increment in FPA was observed after $72 \mathrm{~h}$ by $T$. reesei. On the other hand, higher CMCases were achieved by Aspergillus strains followed by $T$. viride and $N$. crassa. A sharp increment in the CMCase has been observed till $72 \mathrm{~h}$ by Aspergillus strains while CMCase produced by $T$. viride at a steady rate till 120 $\mathrm{h}$ after that period a sharp increment has been observed as viewed from Fig. 7(b).

\section{Effect of Trehalose as Carbon Source on Cellulase Production Under Submerged Cultivation}

Separate sets of batch experiments have been performed to study the effect of trehalose sugar $\left(10\right.$ g. $\left.\mathrm{L}^{-1}\right)$ as a carbon source on cellulase production by various fungal strains under submerged cultivation. Thirumale et al. (2001) reported cellulase formation by trehalose in clostridium papyrosolvens CFR-703. It was observed from Figs. 8(a) and $8(\mathrm{~b})$ that various fungal strains produce significantly lower cellulase activities under the trehalose sugar-based fermentation medium. Maximum cellulase activities (IU. $\mathrm{mL}^{-1}$ ) in terms of FPA and CMCase attained by T. reesei, $T$. viride, $N$. crassa, A. niger and A. fumigatus were 0.831 , $0.589 ; 0.482,1.07 ; 0.158,0.302 ; 0.434,2.18 ; 0.439,1.19$ at 120,$96 ; 120,144 ; 144,120 ; 96,120 ; 96,72$ h respectively. Higher FPA activity was observed by $T$. reesei followed by T. viride and Aspergillus strains under a trehalose-based fermentation medium. A steep increment in FPA activity was observed after $72 \mathrm{~h}$ by $T$. reesei and A. fumigatus strain as observed from Fig. 8(a).

On the other hand, higher CMCases were achieved by $A$. niger followed by $A$. fumigatus strain while $N$. cras- sa showed lower CMCase activity under trehalose-based fermentation medium. A steep increment in the CMCase has been observed after $24 \mathrm{~h}$ by Aspergillus strains as viewed from Fig. 8(b).

\section{Effect of Sorbitol on Cellulase Production Under Submerged Cultivation}

Individual sets of batch experiments have been performed to study the effect of sugar alcohol such as sorbitol (10 g.L $\left.\mathrm{L}^{-1}\right)$ as a carbon source on cellulase production by various fungal strains under submerged cultivation. It was observed from Figs. 9(a) and 9(b) that various fungal strains produce significantly reduced cellulase activities under sorbitol-based fermentation medium. Maximum cellulase activities (IU. $\mathrm{mL}^{-1}$ ) in terms of FPA and CMCase attained by T. reesei, $T$. viride, N. crassa, A. niger and A. fumigatus were 0.709, $0.506 ; 0.312,0.786 ; 0.423,0.795 ; 0.278,1.18 ; 0.239,0.911$ at 120,$96 ; 120,144 ; 144,120 ; 96,120 ; 96,120$ h respectively. Higher FPA was observed by $T$. reesei followed by N. cras$s a$ and $T$. viride strains under sorbitol-based fermentation medium. A steep increment in FPA activities was observed after $48 \mathrm{~h}$ by $T$. reesei as observed from Fig. 9(a), while smooth increments were observed after 96 and $120 \mathrm{~h}$ by $T$. viride and $N$. crassa strains respectively. On the other hand, higher CMCases were achieved by Aspergillus strains followed by $T$. viride and $N$. crassa strains under sorbitol-based fermentation medium as viewed from Fig. 9(b).

\section{Effect of Mannitol as a Carbon Source on Cellulase Production Under Submerged Cultivation}

Separate sets of batch experiments have been performed to study the effect of sugar alcohol such as mannitol (10 g.L $\left.{ }^{-1}\right)$ as a carbon source on cellulase production by various fungal strains under submerged cultivation. It was observed from Figs. 10(a) and 10(b) that various fungal strains produce the least cellulase activities under mannitol-based fermentation

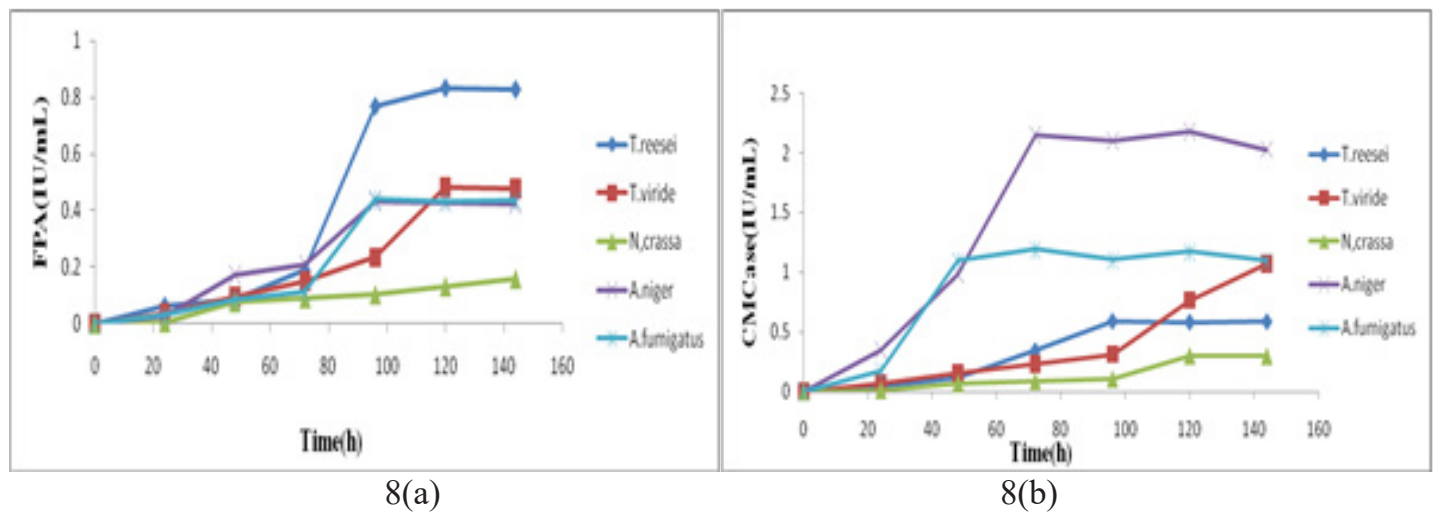

Fig. 8: Comparative FPA and CMCase achieved by various fungal strains under trehalose based production medium at $30^{\circ} \mathrm{C}$ and $\mathrm{pH} 5.0$. 


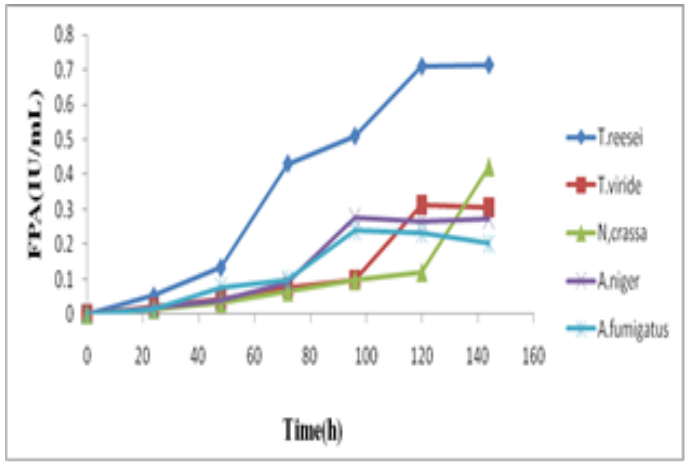

9(a)

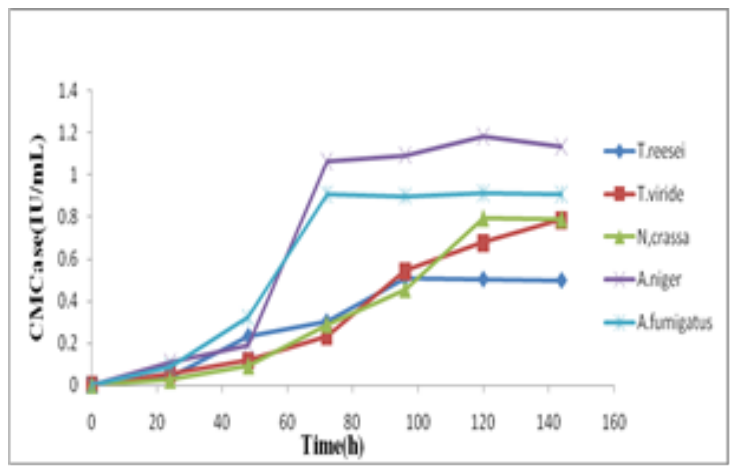

9(b)

Fig. 9: Comparative FPA and CMCase achieved by various fungal strains under sorbitol based production medium at $30^{\circ} \mathrm{C}$ and $\mathrm{pH} 5.0$.

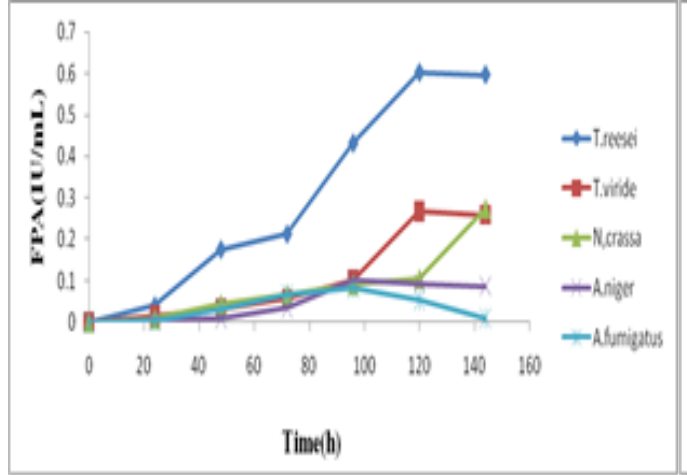

10(a)

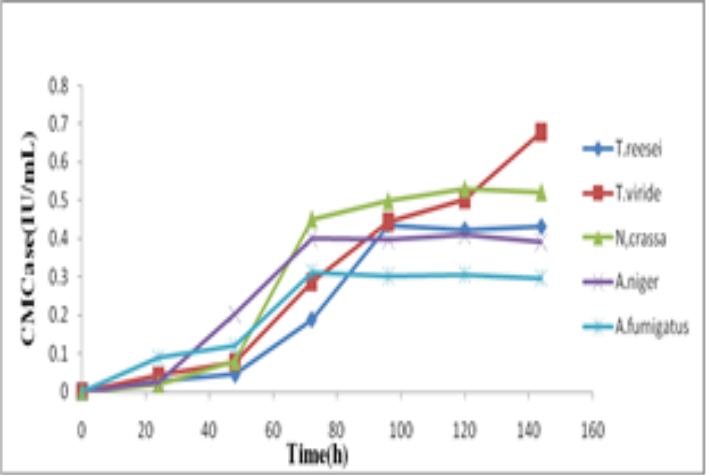

10(b)

Fig. 10: Comparative FPA and CMCase achieved by various fungal strains under mannitol based production medium at $30^{\circ} \mathrm{C}$ and $\mathrm{pH} 5.0$.

medium. Maximum cellulase activities (IU. $\mathrm{mL}^{-1}$ ) in terms of FPA and CMCase attained by $T$. reesei, $T$. viride, $N$. crassa, A.niger and A. fumigatus were $0.602,0.435 ; 0.267$, $0.678 ; 0.274,0.530 ; 0.102,0.411 ; 0.083,0.311$ at 120,96 ; 120,$144 ; 144,120 ; 96,120 ; 96,72 \mathrm{~h}$ respectively. It has been observed from Fig. 10(a) that T. reesei produces higher FPA activity under mannitol-based fermentation medium as compared to the other used fungal strains. On the other hand, significantly good CMCases were observed by all the used fungal strains except $A$. fumigatus strain as viewed from Fig. 10(b). When the cellulase activities of various fungal strains under sorbitol and mannitol-based mediums are examined, it can be concluded that sorbitol-based mediums are considerably more suited for cellulase production than mannitol-based mediums.

\section{Effect of Mixed Pure Sugars as Carbon Source on Cellulase Production Under Submerged Cultivation}

Individual sets of batch experiments have been performed to study the effect of mixed pure sugars (total 10 g. $\mathrm{L}^{-1}$ ) such as cellulose + lactose $(5+5)$, cellulose + xylose $(5+5)$, cellulose + sorbitol $(5+5)$, cellulose + lactose + xylose $(4+3+3)$, cellulose + lactose + sorbitol $(4+3+3)$, cellulose + lactose $+x y l o s e$ + sorbitol $(2.5+2.5+2.5+2.5)$ in $\mathrm{g} . \mathrm{L}^{-1}$ as mixed carbon source on cellulase production by various fungal strains under submerged cultivation. It was observed from Figs. 11(a) (b), 12(a) (b), 13(a) (b), 14(a) (b), 15(a) (b), 16(a) (b) that various fungal strains produce significantly better cellulase activities under carbon sources used as mixed condition than taken singly as lactose, sorbitol and xylose sugars. Ritter et al. (2013) investigated cellulase and xylanase production by $P$. echinulatum in submerged media containing cellulose amended with sorbitol. Maximum cellulase activities (IU. $\mathrm{mL}^{-1}$ ) in terms of FPA and CMCase attained by T. reesei, $T$. viride, $N$. crassa, A. niger and A. fumigatus were 2.93, 2.59; $1.43,3.17 ; 1.39,2.75 ; 0.670,4.03 ; 0.833,3.46$ : 2.29, 2.19; $1.26,2.96 ; 1.08,2.45 ; 0.593,3.75 ; 0.711,3.11: 1.91,1.78$; $1.01,2.41 ; 0.987,2.19 ; 0.523,3.64 ; 0.634,3.01: 2.47,2.11$; 
1.51, 3.02; 1.29, 2.41; 0.541, 3.87; 0.765, 3.32: 2.20, 1.96; $1.31,2.67 ; 1.13,2.34 ; 0.592,3.70 ; 0.751,3.08$ : 2.04, 1.61; $1.09,2.28 ; 0.968,1.96 ; 0.469,2.78 ; 0.557,2.49$ under mixed sugars condition such as $(\mathrm{L}+\mathrm{C}),(\mathrm{X}+\mathrm{C}),(\mathrm{S}+\mathrm{C}),(\mathrm{L}+\mathrm{X}+$ $\mathrm{C}),(\mathrm{L}+\mathrm{S}+\mathrm{C}),(\mathrm{L}+\mathrm{X}+\mathrm{S}+\mathrm{C})$ respectively.

$(\mathrm{C}+\mathrm{L}$ : cellulose + lactose $\mathrm{C}+\mathrm{X}$ : cellulose + xylose; $\mathrm{C}+\mathrm{S}$ : cellulose + sorbitol; $\mathrm{C}+\mathrm{L}+\mathrm{X}$ : cellulose+ lactose+ xylose; $\mathrm{C}+\mathrm{L}+\mathrm{S}$ : cellulose + lactose + sorbitol; $\mathrm{C}+\mathrm{L}+\mathrm{X}+\mathrm{S}$ : cellulose + lactose+ xylose+sorbitol).

Whereas cellulase activities (IU.mL ${ }^{-1}$ ) in terms of FPA and CMCase attained by $T$. reesei, $T$. viride, $N$. crassa, $A$. niger and A. fumigatus were $2.31,1.63 ; 1.26,2.55 ; 1.06$, $2.13 ; 0.433,1.96 ; 0.556,1.98: 1.53,1.15 ; 0.780,1.54 ; 0.639$, $1.30 ; 0.239,1.21 ; 0.341,1.29: 0.709,0.506 ; 0.312,0.786$; $0.423,0.795 ; 0.278,1.18 ; 0.239,0.911$ under single sugars containing fermentation medium such as lactose, xylose and sorbitol respectively.

It has been observed from Figs. 11(a) (b), 12(a) (b), 13(a) (b), 14(a) (b) that cellulases activity is achieved by using fungal strains under mixed sugars (lactose + cellulose), (lactose + xylose + cellulose); (xylose + cellulose); (sorbitol + cellulose) were somewhat higher than lactose, xylose, and sorbitol-based medium taken singly and separately, which suggests that under mixed sugars condition microbes can take both types of sugars either required for growth or for cellulase induction rather than sugars taken singly in fermentation medium having higher growth-promoting with lesser enzyme induction capability. Pure soluble sugars play a significant role in the production process to overcome critical fermentation circumstances (mixing, aeration), and partially adding

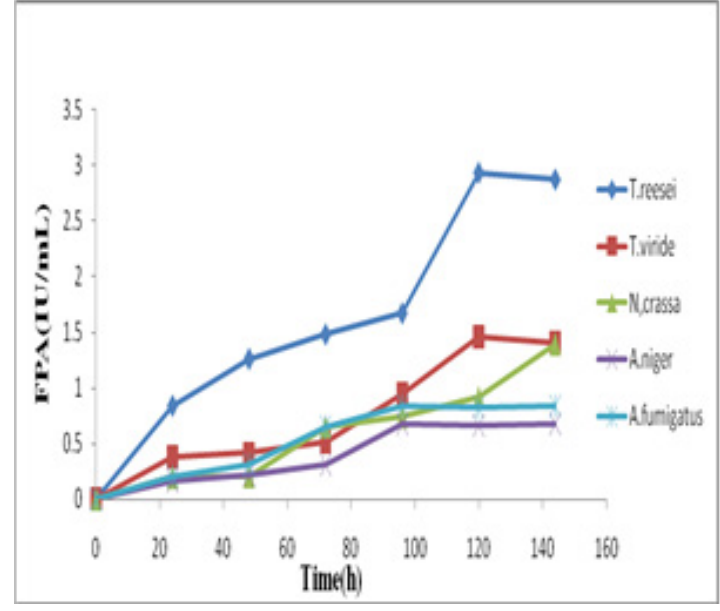

11(a)

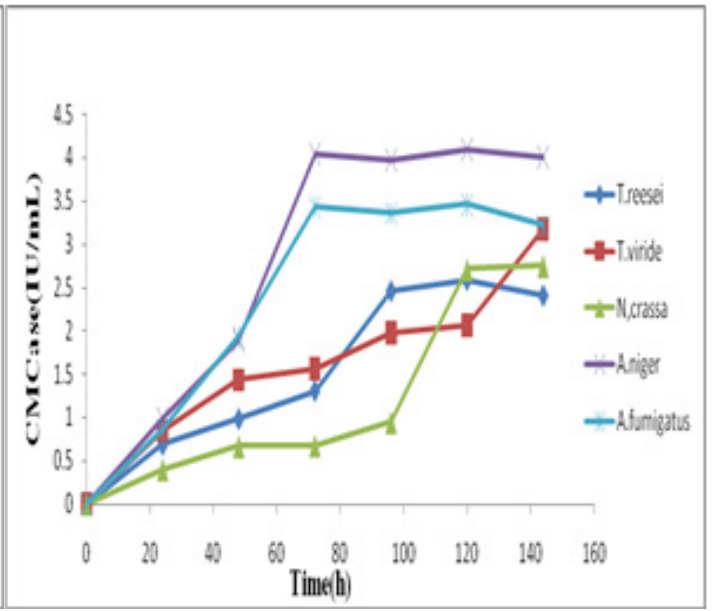

11(b)

Fig. 11: Comparative FPA and CMCase achieved by various fungal strains under cellulose + lactose based production medium at $30^{\circ} \mathrm{C}$ and $\mathrm{pH} 5.0$.

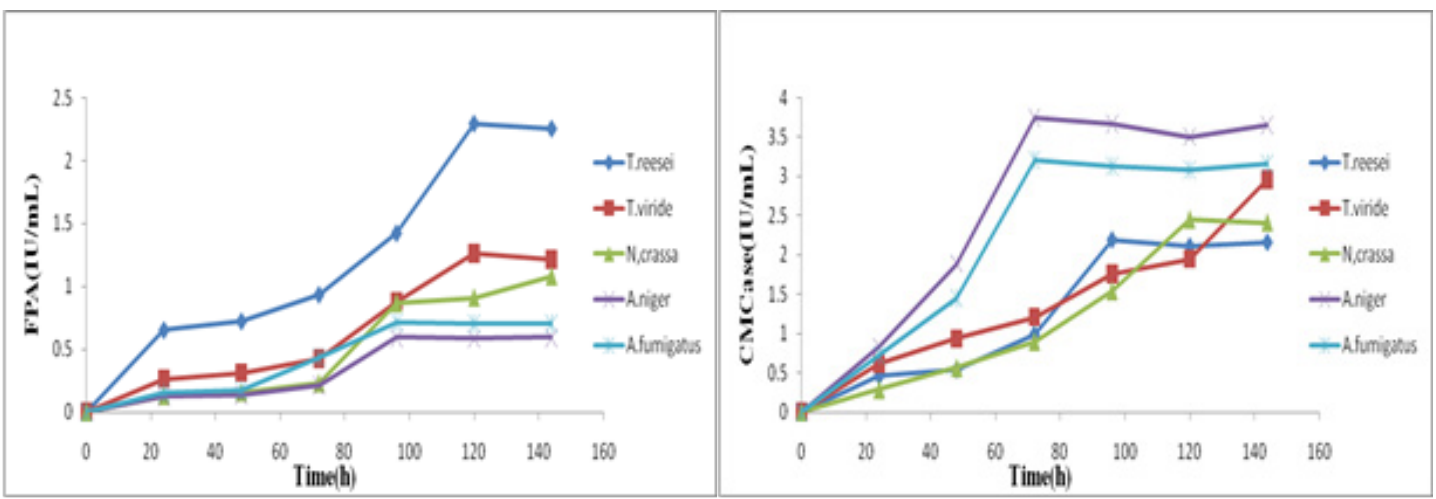

12(a)

$12(\mathrm{~b})$

Fig. 12: Comparative FPA and CMCase achieved by various fungal strains under cellulose + xylose based production medium at $30^{\circ} \mathrm{C}$ and $\mathrm{pH} 5.0$. 
insoluble cellulose to soluble sugar-based media may boost cellulase induction capability while maintaining a smooth fermentation condition.

\section{CONCLUSION}

The induction of cellulase production by insoluble carbon source cellulose was a common and efficient strategy, but has some drawbacks, such as difficult fermentation operation, substantial cellulase loss, long fermentation time, and high energy consumption, resulting in the high cost of cellulase production in the industry. These drawbacks can be overcome if soluble carbon sources are used as the inducers for cellulase production. When the cellulase activity produced by fungal strains under pure sugars based liquid-state fermentation was compared, it was discovered that Trichoderma strains produce higher activity under lactose, CMC and sucrose, xylose, trehalose, and sorbitol based medium, whereas Aspergillus strains produce higher activity under maltose and cellobiose, xylose, trehalose based medium. On the other hand, Neurospora showed higher activity under sucrose and maltose and arabinose-based medium while the least activity was observed with lactose-based media. Arabinose sugar was found least effective for cellulase production with Trichoderma and Aspergillus strains. In sugar alcohols, sorbitol was found quite effective for cellulase production as compared to mannitol. Cellulases activity achieved by fungal strains under mixed sugars condition (lactose + cellulose) (lactose + xylose + cellulose) $($ xylose + cellulose $)$ (sorbitol +

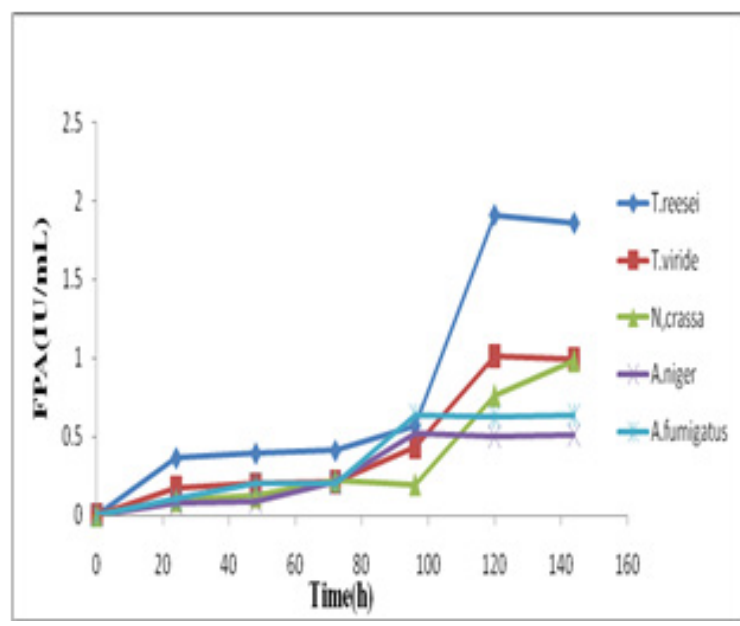

13(a)

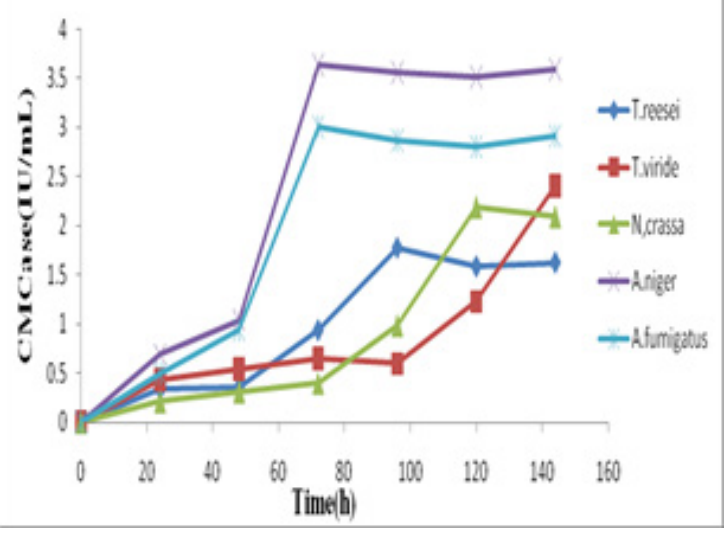

13(b)

Fig. 13: Comparative FPA and CMCase achieved by various fungal strains under cellulose + sorbitol based production medium at $30^{\circ} \mathrm{C}$ and $\mathrm{pH} 5.0$.

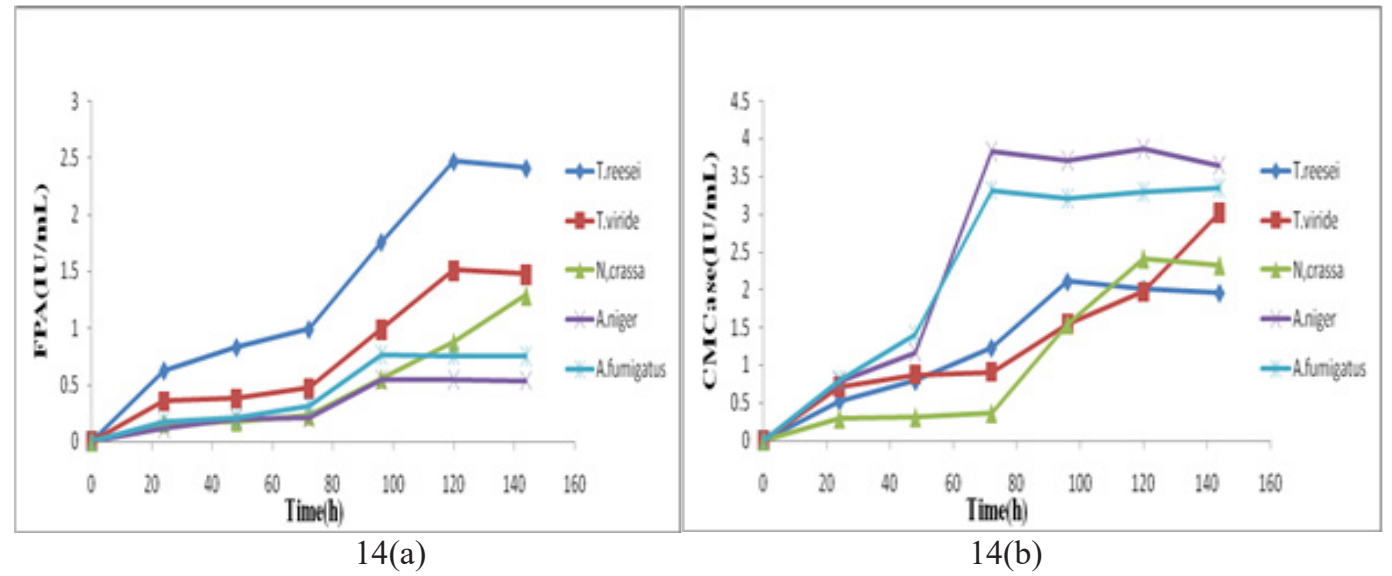

Fig. 14: Comparative FPA and CMCase achieved by various fungal strains under cellulose + lactose + xylose based production medium at $30^{\circ} \mathrm{C}$ and $\mathrm{pH} 5.0$. 


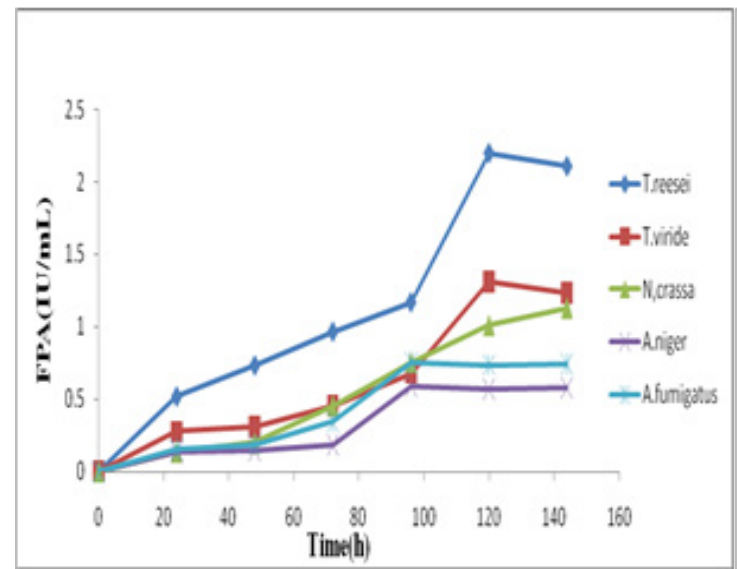

$15(a)$

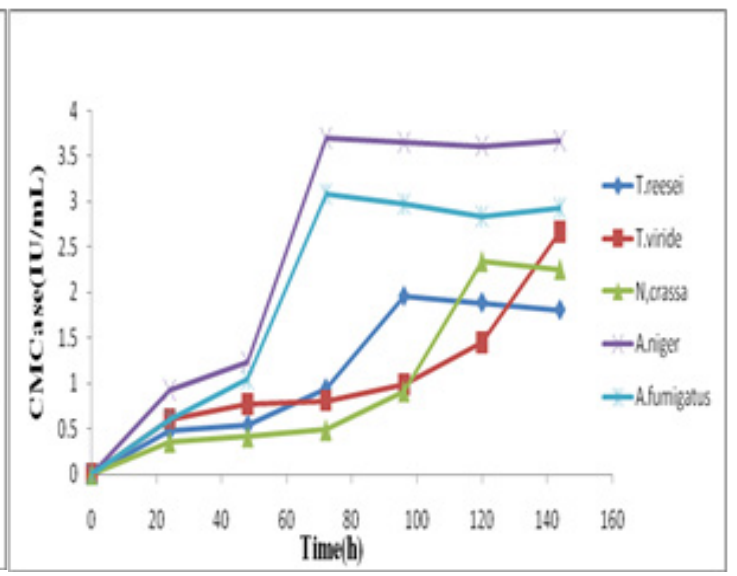

15(b)

Fig. 15: Comparative FPA and CMCase achieved by various fungal strains under cellulose + lactose + sorbitol based production medium at $30^{\circ} \mathrm{C}$ and $\mathrm{pH} 5.0$.

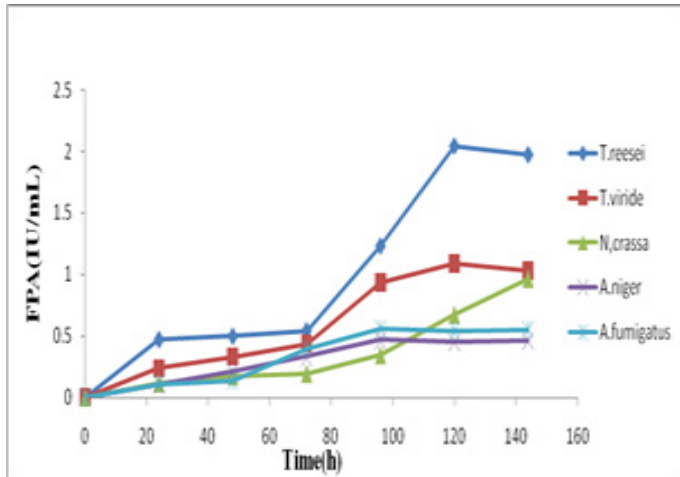

$16(\mathrm{a})$

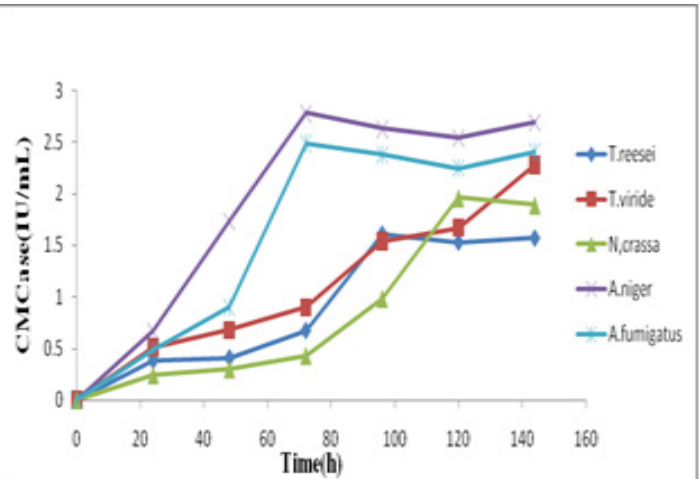

16(b)

Fig. 16: Comparative FPA and CMCase achieved by various fungal strains under cellulose + lactose + sorbitol + xylose based production medium at $30^{\circ} \mathrm{C}$ and $\mathrm{pH} 5.0$.

cellulose) were somewhat higher than only lactose or xylose or sorbitol-based medium. It has also been concluded that different fungal strains used pure sugars and sugar alcohols differently for cellulase induction and production.

\section{ACKNOWLEDGMENTS}

The authors gratefully acknowledged the ministry of human resource and development, India for providing fellowship to carry out present research work.

\section{REFERENCES}

Allan, A.L. and Roche, C.D. 1989. Effects of strain and fermentation conditions on the production of cellulases by T. reesei. Biotechnol. Bioengg., 33: 650-656.

Bhatt, M.K. 2000. Cellulases and related enzymes in biotechnology. Biotechnol. Adv., 18: 355-383.
Binder, A.T.K. and Ghose. C. 1978. Adsorption of cellulose by Trichoderma viride. Biotechnol. Bioengg., 20: 1187-1199.

Cotoras, M. and Agosin, E. 1992. Regulatory aspects of endoglucanase production by the brown rot fungus Gleophyllum trabenum. Exper. Microbiol., 16 253-260.

Domingues, F.C., Queinoz, J.A., Cabral, J.M.S. and Fonseca, L.P. 2004. The influence of culture conditions on the mycelial structure and cellulase production by Trichoderma reesei RUT C 30. Enzyme Microbial Technol., 5: 26-34.

Gautam, S.P., Bundela, P.S., Pandey, A.K., Khan, J., Awasthi, M.K. and Sarsaiya, S. 2011. Optimization for the production of cellulase enzyme from the municipal solid waste residue by two novel cellulolytic fungi. Biotechnol. Res. J., 11: 8-17.

Ghose, T.K. 1987. Measurement of cellulase activities. Pure Appl. Chem., 59(2): 257-268.

Ike M. and Tokuyasu, K. 2018. Cellulase production of Trichoderma reesei (Hypocrea jecorina) by continuously fed cultivation using sucrose as primary carbon source. J. Appl. Glycosci., 65(4): 51-56.

Ivanova, C., Baath, J.A., Seiboth, B. and Kubicek, C.P. 2013. Systems analysis of lactose metabolism in Trichoderma reesei identifies a lactose 
permease that is essential for cellulase induction. PLoS ONE, 8(5): 463.

Janas, P., Targonski, Z. and Mleko, S. 2002. New inducers for cellulase production by Trichoderma reesei -7. Polish Agri. Uni. Food Technol. Series. 5: 14-27

Ju, L.K. and Afolabi, O.A. 1999. Waste paper hydrolysate as a soluble inducing substrate for cellulase production in continuous culture of Trichoderma reesei., Biotechnol Prog., 5: 91-97.

Kamagata, Y., Yachi, M., Kurasawa, T., Suto, M., Sasaki, H., Takao, S. and Tomito, F. 1991. Cellulase induction by cellobiose octaacetate in Penicillium purpogenum. J. Fermentation Bioengg., 72: 217-220.

Li, C., Lin, F., Zhou, L., Qin, L., Li B., Zhou Z., Jin, M. and Chen Z. 2017. Cellulase hyper-production by Trichoderma reesei mutant SEU-7 on lactose., Biotechnol Biofuels. 10: 228.

Lin, J., Zhang, X., Song, B., Xue, W., Su, X., Chen, X. and Dong, Z. 2017. Improving cellulase production in submerged fermentation by the expression of a Vitreoscilla hemoglobin in Trichoderma reesei. AMB Express, 7: 203.

Loewenberg, J.R. and Chapman, C.M. 1997. Sophrose metabolism and cellulase induction in Trichoderma. Archives Microbiol., 113: 61-64.

Maibam, P.D. and Maiti, S.K. 2019. A strategy for simultaneous xylose utilization and enhancement of cellulase enzyme production by Trichoderma reesei cultivated on liquid hydrolysate followed by induction with the feeding of solid sugarcane bagasse. Waste and Biomass Valoriz., 2019: 1-10

Morikova, Y., Ohashi, T., Mantani, O. and Okada, H. 1995. Cellulase induction by lactose in Trichoderma reesei PC3-7. Appl. Microbiol. Technol., 44: 106-111.

Morrison, J., McCarthy, U. and Michal, A.P. 1987. Cellulase production by Taloromyces emersonii CBS 814.70 and a mutant UV7 during growth on cellulose, lactose, and glucose-containing media. Enzyme Microbial Technol., 9: 422-425.

Niranjane, A.P., Madhou, P. and Stevenson, T.W. 2007. The effect of carbohydrate carbon sources on the production of cellulase by Phlebia gigantean. Enzyme and Microbial Technol., 40(6): 1464-1468.
Ritter, C.E.T., Camassola, M., Zampieri D., Silveira, M.M. and Dillon A.J.P. 2013. Cellulase and xylanase production by Penicillium echinulatum in submerged media containing cellulose amended with sorbitol. Enzyme Res., 2013: 9.

Schaffner, O.W. and Toledo, R.T. 1991. Cellulase production by Trichoderma reese $i$ when culture on xylose-based media supplemented with sorbose. Biotechnol. Bioengg., 7: 12-16.

Schuerg, T., Prahl, J.P., Gabriel, R., Harth. S., Tachea, F., Chen, C.S., Miller M., Masson F., He Q., Brown, S., Mirshiaghi, M., Liang, L., Tom, L.M., Tanjore, D., Sun N., Pray T.R. and Singer S.W. 2017. Xylose induces cellulase production in Thermoascus aurantiacus. Biotechnol. Biofuels, 10: 271.

Sehnem, N.T., Bitteencourt, L.R.D., Camassola, M. and Dillon, A.J.P. 2006. Cellulase production by Penicillium echinulatum on lactose. Appl. Microbial. Biotechnol., 72: 1 63-167.

Suto, M. and Tomita, F. 2001, Induction and catabolite repression mechanisms of cellulase in fungi. J. Biosci. Bioengg., 92: 305-311.

Thirumale, S., Rani, D.S. and Nand, K. 2001. Control of cellulase formation by trehalose in Clostridium papyrosolvens CFR-703. Process Biochem., 37(3): 241-245.

Waghmare, P.K.R., Patil, S.M., Jadhav, S.L., Jeon, B.H. and Govindwar, S.P. 2018. Utilization of agricultural waste biomass by cellulolytic isolate Enterobacter sp. SUK-Bio. Agric. Natural Resour., 52(5): 399-406.

Wang, C.H., Hseu, T.H. and Huang, C.M. 1988. Induction of cellulases by cellooligosaccharides in Trichoderma koninghii G-39. J. Biotechnol., 9: 47-60.

Wang, C.H. and Reesei, E.T. 1994. Lactose utilization by fungal system an approach. Enzyme Microbial Technol., 66(3): 506-577.

Wyman, M. and Chen, S. 1992. Cellulase production by Trichoderma reesei using whole wheat flour as a carbon source. Enzyme Microbial Technol., 14: 825-831.

Wyman, M. and Chen, S. 1991. Cellulase production is induced by carbon sources derived from the waste newspaper. Process Biochem., 26: 93-100. 